\title{
STUDI KASUS PADA SISWA X YANG MEMILIKI PERILAKU \\ PACARAN MENYIMPANG DI SMP NEGERI I MADANG SUKU II
}

\author{
Ayu Sri Astuti ${ }^{1}$, Moh. Edwar Romli², Syska Purnama Sari ${ }^{3}$ \\ Universitas PGRI Palembang \\ Email: ayuastuti38812@gmail.com \\ Universitas PGRI Palembang \\ Email: edwarromli@gmail.com
}

\begin{abstract}
ABSTRAK
Tujuannya penelitian ini untuk megetahui bentuk-bentuk siswa yang memiliki perilaku pacaran menyimpang, mengetahui faktor sisiwa yang memiliki perilaku pacaran menyimpang, mengetahui dampak dari siswa yang memiliki perilaku pacaran menyimpang, mengetahui peran guru BK dalam mengatasi siswa yang memiliki perilaku pacaran menyimpang. Jenis penelitian yang dilakukan pada penelitian ini adalah jenis penelitian kualitatif dengan metode pengumpulan datanya menggunakanpenelitian lapangan yaitu peneliti dengan mengamati langsung ke lokasi penelitian atau subyek yang akan diteliti. subyeknya secara langsung dan melalui pengamatan. Setelah semua data yang diperlukan telah terkumpul, lalu dianalisis. Teknik analisisnya dengan cara reduksi data, penyajian data, dan verifikasi.Hasil penelitian adalah bentuk perilaku pacaran menyimpang bersentuhan,berciuman,berpelukan. Faktor keluarga, kelompok bermain, media masa. Dampak prestasi sekolah menurun, pergaulan sekolah, mengisi waktu luang, perasaan nyaman dan peran guru BK.
\end{abstract}

Kata Kunci: Siswa x Yang Memiliki Perilaku Pacaran Menyimpang

\section{CASE STUDY ON STUDENT X WHO HAVE DIFFERENT DATE BEHAVIOR IN JUNIOR HIGH SCHOOL NEGERI 1 MADANG SUKU II}

\begin{abstract}
The purpose of this study is to know the forms of students who have deviant courtship behaviors, to know the underlying factors that have deviant courtship behaviors, to know the effects of students who have deviant courtship behaviors, to know the role of the bk teacher in coping with deviant courtship behaviors. The type of research conducted on this study is a qualitative study using the methods of data collection using fiel research that is, researchers by looking directly at the research site or on the subject. The subject is both direct and observation. After all the necessary data has been collected, then analyzed. Its analysis techniques involve data reduction, data presentation, and verification. Research results from a form of deviant courtship behavior... touching, kissing, hugging. Family factors,
\end{abstract}


play groups, media. The impact of school performance is reduced, school associations, leisure time, comfort and the role of a school guidance counselor.

\section{Keywords: Students X Who Have Deviant Dating Behavior}

\section{PENDAHULUAN}

Saat ini banyak terjadi perubahan -perubahan perilaku remaja. Semakin berkembang zaman semakin pesatnya tingkah laku yang dilakukan oleh remaja memiliki perilaku pacaran yang menyimpang. Pacaran merupakan perkenalan antara dua insan manusia yang biasanya berada dalam rangkaian tahap pencarian kecocokan menuju kehidupan berkeluarga yang dikenal dengan pernikahan.

Akan tetapi banyak orang yang belum cukup umur serta masih belum memiliki persyaratan untuk menuju jenjang pernikahan telah banyak melakukan tradisi ini yang sebenarnya belum tahu masalah tersebut. Tetapi pada kenyataannya tidak semua bentuk pacaran itu bertujuan kepada jenjangan pernikahan dan berkeluarga. Banyak sekali diantara pemuda pemudi khusnya remaja ABG (Anak Baru Gede) yang lebih terdorong oleh rasa keterkaitan semata, disebabkan dari sisi kedewasaan, usia kemampuan rumah tangga (berkeluarga), mereka belum mampua atau belum bisa.

Perilaku pacaran yang dilakukan remaja saat ini telah jauh menyimpang dari perilaku moral. Dengan perbuatan tersebut remaja kita menjadi generasi pemalas, pembohong yang selanjutnya dapat melumpuhkan soladaritas mereka terhadap agama, melunturkan kemulian, menandai moral serta menghancurkan keperibadian dan melemahkan ingatan. Selain itu terdapat beberapa bahaya seperti yang dikemukakan Ulwan dalam bukunya luqman el-hakim. Adanya bahaya terhadap kesehatan, hal ini bisa menimpa remaja siapa saja jika dalam pacaran mereka sudah kelewatan batasa dan melakukan hal-hal negatife seperti berhubungan seks dengan lawan jenis. Adanya bahaya sosial, moral, dan psikologis.

\section{METODE PENELITIAN}

Dalam usaha untuk melakukan sebuah penelitian, penelitian memerlukan suatu metode yang tersusun secara sistematik dengan tujuan agar data yang diperoleh oleh peneliti merupakan data yang valid sehingga peneliti ini layak 
untuk diuji kebenaranya dan manfaat penelitian ini dapat dirasakan. Oleh karena itulah penelitian ini dibutuhkan metode yang sesuai.

Jenis penelitian ini adalah penelitian deskriptif kualitatif. Adapun yang dimaksud dengan peneliti kualitatif merupakan suatu peneliti yang berlatar belakang ilmiah, yaitu menjabarkan fenomena ataupun kejadian yang sedang terjadi menggunakan metode yang ada, yaitu wawancara, observasi, serta dokumentasi.

Peneliti kualitatif menjabarkan tentang kejadian yang saat itu sedang dialami oleh subjek penelitian misalnya saja perlu subjek ataupun tindakantindakan lainya yang dilakukan subjek. Dalam penelitian ini, penelitian kualitatif deskritif akan digunakan untuk mendeskripsikan mengenai Siswa X Yang Memiliki Perilaku Pacaran Menyimpang bagi siswa SMP Negeri I Madang Suku II.

\section{HASIL DAN PEMBAHASAN}

\section{HASIL PENELITIAN}

Berdasarkan dari hasil observasi dan wawancara yang telah dilakukan oleh peneliti kurang lebih seminggu di SMP Negeri I Madang Suku II. Teori Sparinah Sandil Persepsi Social Mengenai Perilaku Menyimpang Setelah dilakukan penelitian didapati bahwa "NA" juga memiliki sejumlah faktor protektif diantaranya yaitu faktor protektif dari dalam diri sendiri dan dari luar, dimana faktor tersebut dapat menekan perilaku pacaran menyimpang "NA". Sesuai dengan pengertian faktor protektif menurut penulis, dan benar menurut Division \& Health (2: 2011) yang berarti faktor yang dapat melindungi atau faktor yang dapat mengurangi, mengendalikan, bahkan menghilangkan perilaku negatif seseorang. "NA" sendiri terkait dengan perilaku pacaran menyimpang memiliki beberapa keadaan yang merupakan faktor protektif perilaku pacaran menyimpang yang dimilikinya. (Rahyani, 2014) pertama yaitu, nilai-nilai yang diyakini, persepsi, motivasi untuk menghindari perilaku seks berisiko, niat, serta keterampilan yang memadai untuk menolak hubungan seks pranikah.

Mengenai Perilaku Menyimpang, sebelum subyek ketemu dengan pacarnya terlebih dahulu dandan/berhias, setelah ketemu berdua melakukan bersentuhan dan dimulai dengan berpegangan tagan sampai berpelukan. Itu sudah kebiasaan 
mereka berdua setiap bertemu, mau ditempat sepi maupun ditempat ramai mereka berdua tidak merasa malu sama sekali itu sudah hal biasa dikalangan remaja, sekarang kebanyakan seperti itu seperti dunia milik mereka berdua. (Fedyani \& Martua,1997)

Sehabis tahap bersentuhan adalagi adegan berciuman yang dimaksud yaitu berciuman tidak seperti ibu mencium anaknya tetapi sekarang berciman bibir sama-sama memainkan lidah dimulutnya, dan ada lagi bercumbu bersama kekasihya yang dimaksud dengan bercumbu adalah menyentuh bagian sensitive dari tubuh kekasihya dan mengarah kepada pembangkitan gairah seks tapi biasanya subyek ini melakukanya dengan kekasinya sendiri ditempat sepi ini lah yang terjadi saling nafsunya, bagaimana tidak terjadi mereka melakukanya ditempat yang sepi jadi terlihat tidak ada orang maka dari itu mereka berpikir untu melakukannya.

Sekarang dikalangan remaja semakin rusak dengan adanya pacaran yang seperti ini, apalagi kurang pantaan terhadap orang tua maupun keluarga kasih sayang dan perhatian terhadap orang tua, dan menyalah gunakan kepercayaanya tergantung dengan diri kita sendiri dan lingkungan juga bisa menjadi faktor dan sekeliling kita, jadi kita tidak bisa menyalahkan kedua orang tua karena ini semua kesalahan kita yang tidak bisa menjaganya.

Penyebab subyek tersebut menjadi seperti itu dari faktor keluarga yang terlalu sibuk dengan pekerjaan yang tidak memperhatikan anak-anaknya sehinga melalukan hal-hal yang memalukan bagi keluarganya sendiri, yang keluarga fikirkan hanya bagaimana cara membahagiakan anak-anaknya kedepanya seperti berkrcukupan dengan harta dan kekayaan yang dimiliki orang tuanya, subyek hanya menginginkan orang tua memperhatiak anak-anaknya supaya menjadi lebih baik, baik dikalangan keluarga maupun dikalangan masyarakat.

Dari faktor teman main atau teman-teman sebaya (Basse \& Rahayani 2014:9) yang ada disekolahan juga bisa menjadikan kita buruk perilakunya, tergantuang kita memilih teman, ketia kita mendapatkan teman yang buruk kita akan mengarah perilaku yang buruk dan ketika kita mendapat teman yang baik maka kita akan mengarah perilaku yang baik tapi sulit di zaman sekarang mencari 
teman baik untuk itu selalu menjaga diri kita jangan merusak semuanya menjadi buruk.

\section{PEMBAHASAN}

Hal ini didukung dari Magdelena (2010:33) media masa juga bisa mempengaruhi pergaulan anak-anak yang belum mengerti dampak sosial media, subyek bisa seperti ini karena selalu menyalah gunakan media dari HP awal pacaran hanya bisa-biasa aja ketia menyalah gunakan media sosial jadi berfikir buruk karena sudah mengetahui bentuk-bentuk pacaran zaman sekarang dimedia sosial, sekarang banya media sosial yang mengambarkan pacaran zaman sekarang seperti berciuman, berperlukan sampai melakukan hubungan seks maka berhatihatilah dalam mengambil lngkah untuk melihat medis sosial ambil yang positif dan tingalkan yang buruk supaya kedepanya menjadi lebih baik.

Perilaku menyimpang berpacaran memiliki dampak posotif dan negatif, seperti prestasi sekolah, pergaulan sekolah, mengisi waktu luang, perasaan aman, tenang/nyaman, dan setres menurut (kartono 2003)

Prestasi seseorang bisa meningkat karena pacaran. Umumnya prestasi akan meningkat apabila seseorang mendapat dukungan dan semangat dari pacar, sebaliknya prestasi akan menurun apabila terjadi permasalahan yang cukup berat dan mengganggu konsentrasi dalam belajar. Disini subyek dengan prestasi sekolahnya menurun, karena pacar subyek tidak mendukung dengan permasalahan sekolahan, padahal disini juga sama-sama sekolah dalam satu sekolahan, yang dipentingkan cowok "NA" dengan pacaran mereka tidak mementingkan sekolah, hal yang paling utama menurut mereka berpacaran jadi semenjak "NA" berpacaran prestasinya semakin menurun di karenakan sibuk dengan kepentingan mereka yang berpacaran.

Pergaulan dengan teman sebaya bisa meluas menyempit. Pergaulan akan menyempit apabila sepasang kekasih lebih banyak menghabiskan waktu berdua. Semakin lama seseorang akan tergantung pada pasangannya dan menutup diri dari pergulan teman. Iya disini subyek menutup diri dengan teman-temannya beda dengan yang dulu sebelum berpacaran.

Mengisi waktu luang bisa tambah beraktifitas jika keinginan berpacaran dilakukan dengan hal-hal seperti olah raga bersama, berkebun, memelihara 
binatang dan sebagainya. Sebaliknya yang digunakan mereka untuk mengisi luang waktunya dengan digunakan negatif seperti menonton video porno dan banyak lagi yang mereka tonton, itu juga biasanya mereka melakukan/ menirukan yang sedang mereka tonton.

Perasaan aman tenang nyaman hubungan emosional yang terbentuk dalam pacaran akan menimbulkan perasaan aman, serta nyaman jika pacaran dilakukan dengan baik. Akan tetapi jika perasaan nyaman dan aman didapat karena keintiman fisik maka yang timbul bukanlah kasih sayang tetapi nafsu. Karena itu perlu upaya yang kuat membatasi diri.Perbedaan karakteristik akan menjadi hubungan dengan pacaran terkadang dihadapkan pada masalah-masalah yang dapat membuat kita stres karena pikiran yang terlalu berlebihan akan hubungan yang sedang dijalani.

Guru BK memiliki belum berperan penting disekolah untuk membantu siswa-siswanya di lingkungan sekolah agar tidak melakukan tindakan-tindakan yang kurang pantas, salah satu pacaran, yaitu dengan memberikan pengarahan, masukan dan meluruskan perilaku mereka yang kurang pantas melalui salah satu layanan BK yaitu . Konseling individu itu sendiri adalah upaya bantuan yang dilakukan oleh guru BK selaku konselor kepada siswa (konselor) dengan tetap muka secara langsung yang membahas berbagai masalah yang dialami konselor agar konselor memahami kondisi dirinya sendiri, lingkungan, permasalahan, yang dialami, kekuatan dan kelemahan dirinya, serta kemungkinan upaya untuk mengatasi masalahnya.

\section{KESIMPULAN}

Pelayanan bimbingan dan konseling hendaknya berlangsung secara efektif membentuk siswa mencapai tujuan-tujuan perkembangan dan mengatasi permasalahanya termasuk membimbing para siswa untuk berperilaku disiplin. Hal ini menyebabkan perlunya pelayanan bimbingan dan konseling disamping kegiatan pengajaran pelayanan bimbingan dan konseling merupakan hal yang dilakukan oleh guru bimbingan dan konseling dalam mengatasi berbagai permasalahan siswa dalam kegiatan belajar mengajar. Permasalahan tersebut mencakup permasalahan yang terjadi dilingkungan sekolah. Manfaat bimbingan 
dam konseling yang dilakukan oleh guru bimbingan konseling cukup penting bagi seorang siswa untuk mengatasi berbagai permasalahan pribadi siswa.

\section{DAFTAR PUSTAKA}

Abdullah Nashih Ulwan dan Dr. Hassan Hathout, Pendidikan Seks, Bandung: Remaja Rosdakarya, 1992.

Alaska Devision of Behavioral Health. 2011. Risk and Protective Factros for Adolescent Substance Use.

Bowman. 2016. Sosiologi Perkembangan

Cholid Narbuko \&Abu Achamadi, Metode penelitian, (Jakarta: Bumi Aksara), hlm..54

Daud, Muhamad. 2017. Perilaku Pacaran Dikalangan Pelajar SMP Negeri, 1 Belat Di Desa Penarah Kecamatan Kabupaten Karimun. Tanjung Pinang: Universitas Maritim Raja AliHaji. Diambil dari http://jurnal.umar.ac.id/wp-content/uploads/gravity.../JURNALMUHAMAD-DAUD.pdf diakses tgl 26 september 2017 pukul13.30

DeGenova, M.K \& Rice, F.P. 2005. Intimate Relationship, Mirriages, andFamalies, New York: McGraw-Hall.

Dhori, Taufiq Rohman, dkk. 2003. Sosiologi, Yudistira

Fedyani, A \& Martua, IH, Seksualitas Remaja, Jakarta: Pustaka Sinar Harapan, tt.

Hardjana, A., M. 2002. Kiat Berpacaran, Yogyakarta: Kanisius.

Kartono. 2003. Patologi Sosial 2. Kenakalan Remaja.PT Raja Grafindo Persada, Jakarta.

Kartono, K. 2009. Psikolok Abnormal dan Abnormalitas Seksual Bandung: CV Mandar Maju.

Kartono,Kartini. 2010. Patologi Sosial 2 Kenakalan Remaja PT Raja Grafindo

Khusnul Khotimah "Penanganan Perilaku Seksual Penyadang Tunagrahita Di Sekolah Luar Biasa C Wiyata Dharma II Sleman Yogyakarta”.Skripsi tidak diterbitkan UIN Sunan Kalijaga 2007.

Luqman el-Hakim. 2014. Fenomena Pacaran Dunia Remaja, Riau: Zanafa Pubishing.

Marlynda, L. 2017. Upaya Guru Bimbingan Konseling Dalam Mangatasi Perilaku Menyimpang Berpacaran Siswa. Jurnal Edukasi: Jurnal Bimbingan Konseling, 3(1), 40-57. (Online), https:// jurnal.ar-raniry,ac.id/ index. $\mathrm{Php} /$ coba BK/article/view/1413, diakses pada 14 februari 2018). 
M, Magdalena. 2010. Melindungi anak dari seks bebas. Jakarta: PT Grasindo.

Mulyono, Y, Bambang. 1993. Pendekatan Analisis Kenakalan Penanggulangannya. Kanisius. Jakarta.

N, Rahyani. 2014. Intensitas Komunikasi Tentang Seks Dengan Teman Sebaya Sebagai Faktor Risiko Perilaku Inisiasi Sesk Pranikah Remaja di Bali. Yogyakarta: Universitas Gajah Mada. Thesis.

Romaeti, Siti. 2011. Dampak Pacaran Terhadap Moralitas Remaja Menurut Pandangan ustadz Jefri Al Bukhari. Skripsi, Jakarta: Universitas Negeri Islam Syarif Hidayatulloh. Diambil dari http://repositrory, uinjkt.ac.id/dspace/bitdtream/123456789/.../SITI\%20ROMAETI-FITK pdf di akses pada tgl 26 september 2017 pukul 14:00.

Sugiyono. 2010. Metode Penelitian KualitatifKuantitatif dan $R \& D$. Bandung: Alfabeta.

Sumanto, Metodelogi. 1995. Penelitian Sosial dan pendidikan Aplikasi Metode Kualitatif dan Statistik. Jakarta : Andi Offset.

Wikipedia Ensiklopedia Bebas Berbahasa Indonesia, "Pacaran", http://id. Wikipedia.org/wiki/Pacaran,17/12/2003.

Yatimin. 2003. Etika Seksual dan Penyimpangannya Dalam Isalam. Pekanbaru: Penerbit AMZAH. 